\title{
Occurrence of high concentrations of a unique degradation product of chlorophyll- $a$ in particles residing below the thermocline throughout a period of oxygen depletion in Lake Kinneret
}

\author{
Yosef Z. YACOBI*, Ilia OSTROVSKY and Helen M. TALBOT ${ }^{1)}$ \\ Israel Oceanographic and Limnological Research, Kinneret Limnological Laboratory, P.O. Box 447, Migdal 14950, Israel \\ ${ }^{1)}$ School of Chemistry, University of Bristol, Cantock's Close, Bristol, BS8 1TS, UK. Current address: Fossil Fuels and \\ Environmental Geochemistry Newcastle Research Group (NRG), Drummond Building, University of Newcastle, Newcastle-upon- \\ Tyne, NE1 7RU, UK \\ *e-mail corresponding author: yzy@ ocean.org.il
}

\begin{abstract}
An unrecognized chlorophyllous pigment, designated Pheob4, was the most abundant degradation product of chlorophyll-a (Chla) in the hypolimimnion, benthic boundary layer and sedimenting particles in Lake Kinneret in June-July 1997, when a prolonged period of residual oxygen concentration was found below the thermocline. The highest concentration of Pheob4 was found in the benthic boundary layer, where it reached as high concentration as $2 \mu \mathrm{g} \mathrm{l}^{-1}$. In sediment traps positioned below the thermocline Pheob4 constituted from about 5 to 20\% of the Chl-a concentration and in bottom sediments from 5 to $185 \%$. Pheob4 was not detected in epilimnetic water samples, but was found in sediment traps located within the oxygenated water column, within the range of surface wave action. Comparison of regular traps, with traps poisoned by formaldehyde indicates that the importance of Pheob4containing particles in the sedimentation flux is relatively low, and that the bulk of Pheob4 found in the bottom sediment is apparently a result of Chl-a transformation in situ by biological activity. The timing and location of Pheob4 appearance coincided with the lake compartments where denitrification apparently took place. This suggests that Pheob4 may be used as a target pigment to trace organic matter processing under transient conditions in the water column and on the bottom sediments. Pheob4 was tentatively identified as $13^{2}, 17^{2}$ cyclophaeophorbide-a enol. But, since the identification was done on a different system than the one used for the analysis of most of the samples, further investigation is required to verify that finding.
\end{abstract}

Key words: denitrification, sediment traps, $13^{2}, 17^{2}$ cyclophaeophorbide a enol, benthic boundary layer

\section{INTRODUCTION}

Phytoplankton is often the largest contributor to the inventory of organic particles in the water column in natural water bodies, and its decomposition is, therefore, a major process for the recycling of organic matter, and a major source of the flux of sinking particles. The pathways of transformation of the particulate organic material are apparently diverse and highly specific for different components. In the case of phytoplankton, a first-order approach to estimate decomposition is feasible, by monitoring the fate of chlorophyll- $a(\mathrm{Chl}-a)$ in the suspended and sedimenting particles in the water column. Chlorophyll- $a$, is a ubiquitous component of all oxygenic autotrophs, and is degraded by losing or substitution of atoms and residues linked to its central tetrapyrrole scaffold. Although some degradation may occur in intact cells, the majority of the degradation processes take place upon the death of cells. Chl- $a$ is finally transformed to colorless substances, but some proportion of colored, partially degraded molecules reach the bottom and are preserved in sediments. There are some tens of recognized Chl- $a$ degradation products (e.g., Eckard et al. 1991). The pathway leading to the formation of most of those degraded forms of Chl- $a$ is un- known, not even the environmental factors inducing their appearance. There are some exceptions, like the massive formation of chlorophyllide- $a$ following the collapse of diatom blooms (Gieskes 1991), or the formation of pheophorbide- $a$ as a result of zooplankton grazing (Vernet \& Lorenzen 1987). But even the appearance of those substances is not always predictable (Klein et al. 1986; Barlow et al. 1988; Strom 1993).

In most cases the concentration of Chl- $a$ degradation products in the epilimnetic water column is low, and the number of chloropigments observed is limited. On the other hand, sedimented particles are characterized by an abundance of Chl- $a$ degradation products, and often are found in relatively high concentrations (Leavitt 1993).

The goal of the current study was to investigate the suite of Chl- $a$ degradation products affiliated with the period between total depletion of oxygen below the thermocline and the onset of sulfate reduction. This time interval is normally short in Lake Kinneret (Serruya 1978), but an unusual opportunity was available in June-July 1997, when the hypolimnetic anoxia prior to sulfate reduction lasted for a relatively long period, due to an exceptional phytoplankton succession (see below). We found that the most conspicuous Chl- $a$ degradation product in the hypolimnion and in the sediments was a 
Tab. 1. Period of exposure and the depth of placement of traps deployed in Lake Kinneret in JuneJuly 1997. The lower traps in station A, B and F and the traps located in stations H and M were located about $1 \mathrm{~m}$ above the bottom. Station A is positioned in the deepest point in the lake. Other stations were positioned along a transect that spanned between that point and the northwestern shore of the lake.

\begin{tabular}{llllllll}
\hline Exposure period & $\mathrm{A}_{\text {mid }}$ & $\mathrm{A}_{\text {low }}$ & $\mathrm{B}_{\text {mid }}$ & $\mathrm{B}_{\text {low }}$ & $\mathrm{F}_{\text {low }}$ & $\mathrm{M}$ & $\mathrm{H}$ \\
\hline 4-18 Jun & 14.1 & 39.1 & 16.3 & 28.3 & 21.4 & & \\
18 Jun - 2 Jul & 13.9 & 38.9 & 16.1 & 28.1 & 21.2 & & 8.9 \\
15-28 Jul & 16.6 & 38.6 & 17.8 & 27.8 & 20.9 & 13.1 & 8.5 \\
\hline
\end{tabular}

unique substance that we did not found previously in the lake when fully mixed (Yacobi \& Ostrovsky 2000) or with a completely oxygen devoid hypolimnion (Ostrovsky \& Yacobi 1999).

\section{METHODS}

Samples were withdrawn from the water column on 30 June and on 24 July 1997, with a 5-litre AbergRodhe sampler. Collected water samples were preserved in opaque plastic carboys until processing in the laboratory. Traps were deployed in Lake Kinneret in several locations and depths between 4 and 18 June, 18 June and 2 July, and between 15 and 28 July 1997 (Tab. 1). The technical details of the traps installation and location are specified elsewhere (Koren \& Klein 2000). Traps located in stations $\mathrm{H}$ and $\mathrm{M}$ collected particulate material from constantly oxygenated water. The lower traps in stations $\mathrm{A}, \mathrm{B}$ and $\mathrm{F}$ resided within the benthic boundary layer (BBL), about $1 \mathrm{~m}$ above the bottom. The higher traps in stations A and B were located within the hypolimnion. A detailed description of Lake Kinneret thermal stratification, and the chemical environment affiliated with, is outlined in Nishri et al. (2000). In stations $\mathrm{A}, \mathrm{B}$ and $\mathrm{F}$ pairs of traps were positioned, one without any treatment and the other with addition of 10 $\mathrm{ml}$ of concentrated formaldehyde solution contained in a dialysis bag.

Bottom sediment samples were collected manually by a SCUBA diver along a transect that spanned from the north-western shoreline of Lake Kinneret to the lake center (Fig. 1 in Nishri et al. 2000). The transect was sampled from June 10 to July 3 . The uncertainties affiliated with such a relatively long sampling period of a single transect have been discussed extensively elsewhere (Ostrovsky \& Yacobi 1999, Ostrovsky 2000).

Additional samples were collected along an offshore transect near the eastern shore on 7 July 1997. The method of sampling used allows a precise collection of the most recent bottom sediments from the upper fewmm layer (Ostrovsky 2000). In previous studies, we calculated that a diver was able to gather a sediment layer thinner than the layer that could be accumulated during approximately the four summer-fall months preceding the sampling (Ostrovsky \& Yacobi 1999). As the accumulation rate during winter-spring months was a few times higher than in summer-fall (Koren \& Ostrovsky, in press), the layer sampled in this study was apparently less than 2 months old.

The processing of the particulate matter collected from the water column, traps and bottom sediments was as specified elsewhere (Yacobi \& Ostrovsky 2000). Determination of the content of total suspended matter and the concentration of organic matter within, was performed on sub-samples treated immediately, while other sub-samples were stored at $-18{ }^{\circ} \mathrm{C}$ until further processed for pigment analysis. Dry matter (DM) was estimated by drying of material at $80{ }^{\circ} \mathrm{C}$ for $24 \mathrm{~h}$. The losses on ignition, equivalent to the organic matter (OM) content, were measured by ignition of DM in a muffle furnace at $550{ }^{\circ} \mathrm{C}$ for $1 \mathrm{~h}$.

The detailed treatment of samples, protocols used for pigment extraction and separation by HPLC were described elsewhere (Yacobi et al. 1996, Ostrovsky \& Yacobi 1999). Pigment detection was performed with the detector set to $640 \mathrm{~nm}$, in order to suppress the appearance of carotenoids on the chromatograms. Extraction of sedimented particles in organic solvents results in a high number of pigments, and inclusion of all those substances simultaneously makes quantification difficult. In addition, an overlapping of pigments is not a rare phenomenon, and our intention to gain maximal information possible on chlorophyllous pigments guided us in our decision to use the detector as indicated.

The quantification of the chromatograms was facilitated by injection of standards of known concentrations into the HPLC system, and calculating the response factor based on the area under the peak. As we did not have a standard for most of the degradation products of Chl- $a$, the quantification of those pigments was done using the same response factor calculated for pheophorbide- $a$. All pigment concentrations were normalized to OM basis. All Chl- $a$ degradation products combined were defined as "Total degraded Chl- $a$ ". The term "all chlorophyllous pigments" means Chl- $a$ plus its degradation products.

\section{RESULTS}

During June-July 1997 Chl- $a$ concentrations in the epilimnetic water $\left(7-9 \mathrm{mg} \mathrm{m}^{-3}\right)$ were an order of magnitude higher than those in the hypolimnion. Chlorophyllide- $a$ and pheophorbide- $a$ were the most abundant Chl- $a$ degradation products in the epilimnion, but their 
concentrations were relatively low. In the epilimnion, the concentration of total degraded Chl- $a$ did not surpass $2 \%$ of Chl- $a$.

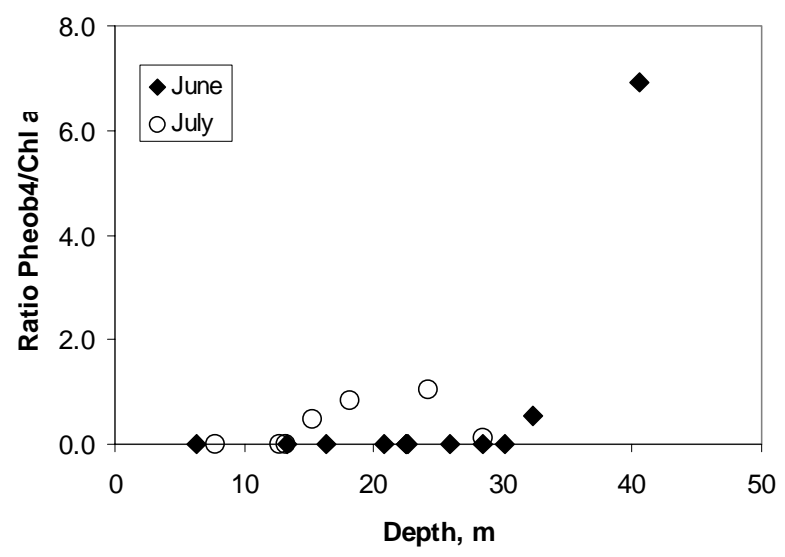

Fig. 1. Ratio of Pheob4 to Chl- $a$ in water column samples, in Stn A, collected in June and July 1997.

A different situation was found in the hypolimnion and the BBL, where Chl- $a$ degradation products were abundant. They were $3-45 \%$ of all chlorophyllous pigments in the hypolimnion and $47-88 \%$ in the BBL. We could identify 8 different $\mathrm{Chl}-a$ degradation products and that showed recurrently in most of the hypolimnetic and BBL samples. On June 30, an unrecognized chlorophyllous pigment was the most abundant degradation product in the BBL. We designated that pigment as Pheob4. Its concentration in the base of the BBL was $1.97 \mathrm{mg} \mathrm{m}^{-3}$, which was about 7 times higher than the concentration of Chl- $a$ in that compartment (Fig. 1). This substance was also present in the upper part of the BBL in conspicuous concentrations, but was absent from the upper part of the water column. Our measure- ments on a shallower station, on July 24, showed that Pheob4 was absent near the bottom, however, it showed in the upper and mid parts of the hypolimnion in concentrations of about $0.5 \mathrm{mg} \mathrm{m}^{-3}$, i.e., in concentrations approximately equal to those of Chl- $a$ (Fig 1).

The suite of chlorophyllous pigments detected in the sedimentation traps was similar to that found in the hypolimnetic water. The concentration of Chl- $a$ in sediment traps positioned in the hypolimnion was about $1.15,1.46$ and $0.73 \mu \mathrm{g} \mathrm{g} \mathrm{OM}^{-1}$, in average, in the first, second and third period, respectively. The concentration of Chl- $a$ in sediment traps positioned in the BBL was about $1.2 \mu \mathrm{g} \mathrm{g} \mathrm{OM}^{-1}$ in the traps positioned throughout the first two deployment periods, and about half of that concentration in the traps deployed throughout the third period. The abundance of different Chl-a-degraded products varied between stations and deployment periods (Tab. 2). In the traps positioned in the hypolimnion the total degraded Chl- $a$ constituted about $15 \%$ of all chlorophyllous pigments in the first and second deployment period, and about $26 \%$ in the third period. Total degraded Chl- $a$ were approximately 26, 22 and $32 \%$ of all chlorophyllous pigments in the traps positioned within the BBL (in the first, second and third period, respectively) and about $35 \%$ in traps positioned in the littoral area. The proportion of different degradation products of Chl- $a$ changed vertically and did not show a discernible pattern. The only exception was the proportion of Pheob4, which showed a clear recurrent pattern of higher Pheob4/Chl- $a$ ratios in the traps positioned in the BBL than in those located in the hypolimnion (Tab. 3). Pheob4 was approximately from 5 to $20 \%$ of Chl- $a$ concentration in the traps positioned in the BBL, but not higher than $1 \%$ in traps positioned in the hypolimnion. In the littoral area, where resuspended material was a dominant fraction of total sedimentation flux (Ostrovsky

Tab. 2. Concentrations of chlorophyll- $a$ and its degradation products in sediment traps positioned within the benthic boundary layer and in the littoral traps in Lake Kinneret. Material was collected throughout three periods of time in 1997: 4-18 June, (I), 18 June, and 2 July (II) and 15-28 July 1997 (III), in the traps positioned in the pelagic waters, and in the littoral throughout the third collection period. Concentrations are expressed as $\mu \mathrm{g}$ pigment $\mathrm{g} \mathrm{OM}^{-1}$. Chld $=$ chlorophyllide; Pheob = peophorbide; Pheon = pheophytin; Pyro $=$ pyrropheophorbide. Pheob1, 2, 3, 4 stand for different undefined chlorophyllous pigments.

\begin{tabular}{|c|c|c|c|c|}
\hline \multirow[t]{2}{*}{ Pigment } & \multicolumn{3}{|c|}{ Pelagic zone } & \multirow{2}{*}{$\frac{\text { Littoral zone }}{\text { III }}$} \\
\hline & $\mathrm{I}$ & II & III & \\
\hline Chld- $a$ & 135.8 & 44.5 & 36.8 & 31.8 \\
\hline Pheob1.- $a$ & 70.1 & 36.8 & 38.5 & 85.6 \\
\hline Pheob.- $a$ & 2.9 & 0.0 & 8.0 & 61.4 \\
\hline Pheob2.- $a$ & 35.9 & 40.3 & 40.3 & 62.3 \\
\hline Pheob3.- $a$ & 21.7 & 0.0 & 18.0 & 11.9 \\
\hline Pheob4.- $a$ & 97.0 & 142.1 & 32.5 & 83.8 \\
\hline Pheon- $a$ & 28.4 & 54.1 & 84.6 & 133.5 \\
\hline Pyro- $a$ & 26.3 & 36.2 & 5.3 & 14.5 \\
\hline Chl- $a$ & 1193.3 & 1273.1 & 562.8 & 867.7 \\
\hline
\end{tabular}


Tab. 3. The ratio of Pheob4 to chlorophyll- $a$ in particles collected in sediment traps in Lake Kinneret throughout three collection periods in 1997: 418 June (I), 18 June and 2 July (II) and 15-28 July 1997 (III).

\begin{tabular}{llccc}
\hline & & \multicolumn{3}{c}{ Collection period } \\
\cline { 3 - 5 } & & I & II & III \\
\hline Station & Lake compartment & & & \\
A & Hypolimnion & 0.008 & 0.009 & $>0.001$ \\
& BBL & 0.053 & 0.085 & 0.025 \\
B & Hypolimnion & $>0.001$ & 0.006 & $>0.001$ \\
& BBL & 0.105 & 0.196 & 0.074 \\
F & BBL & 0.092 & 0.069 & 0.077 \\
H & Epilimnion & & 0.255 & 0.077 \\
M & Epilimnion & & & 0.132 \\
\hline
\end{tabular}

Tab. 4. Comparison of the organic matter content and the ratio of Pheob4 to chlorophyll- $a$ in sediment traps deployed in Lake Kinneret in June and July 1997. Traps poisoned by addition of formaldehyde are designated by " $+\mathrm{F}$ ".

\begin{tabular}{|c|c|c|c|c|c|c|}
\hline & \multicolumn{3}{|c|}{$\begin{array}{c}\text { Organic matter }(\%) \\
\text { Collection period }\end{array}$} & \multicolumn{3}{|c|}{$\begin{array}{l}\text { Ratio Pheob4/Chl- } a \\
\text { Collection period }\end{array}$} \\
\hline & I & II & III & I & II & III \\
\hline $\mathrm{A}_{\text {mid }}$ & 15.4 & 18 & 43.5 & 0.01 & 0.01 & 0.00 \\
\hline $\mathrm{A}_{\mathrm{mid}}+\mathrm{F}$ & 19.7 & 57.3 & 58.3 & 0.01 & 0.21 & 0.00 \\
\hline $\mathrm{A}_{\text {low }}$ & 25.2 & 20.5 & 49.1 & 0.05 & 0.09 & 0.03 \\
\hline $\mathrm{A}_{\text {low }}+\mathrm{F}$ & 29.2 & 22.8 & 64.2 & 0.01 & 0.00 & 0.00 \\
\hline $\mathrm{B}_{\text {mid }}$ & 22.8 & 15 & 44.8 & 0.00 & 0.01 & 0.00 \\
\hline $\mathrm{B}_{\text {mid }}+\mathrm{F}$ & 29.7 & 39.4 & 60.8 & 0.00 & 0.13 & 0.00 \\
\hline $\mathrm{B}_{\text {low }} 29$ & 21.7 & 17.4 & 28.4 & 0.10 & 0.20 & 0.07 \\
\hline $\mathrm{B}_{\text {low }}+\mathrm{F}$ & 23.5 & 18.7 & 58.8 & 0.02 & 0.00 & 0.02 \\
\hline $\mathrm{F}_{\text {low }}$ & 18.7 & 15.3 & 40.8 & 0.09 & 0.07 & 0.08 \\
\hline $\mathrm{F}_{\mathrm{low}}+\mathrm{F}$ & 22.2 & 21.6 & 53.2 & 0.03 & 0.04 & 0.00 \\
\hline
\end{tabular}

\& Yacobi 1999) the concentrations of Pheob4 were high, and relatively more abundant than in the pelagic traps (Tab. 3).

The concentrations of OM measured in traps treated with formaldehyde were in all the cases higher than in non-treated sedimentation traps. The suite of chlorophyllous pigments, and their relative abundance, found in traps treated with formaldehyde was essentially similar to that found in non-treated traps, regardless of trap location and collection period. The only exception was the situation with Pheob4. The Pheob4/Chl- $a$ ratio in the traps positioned within the BBL was lower in formaldehyde-treated traps and than in non-treated traps in all the cases (Tab. 4). In traps positioned within the hypolimnion very little Pheob4 was detected, both in poisoned and non-poisoned traps. Only during the second half of June, poisoned traps positioned in the hypolimnion in Stn A and Stn B contained higher proportion of Pheob4 than non-treated traps (Tab. 4). Throughout that period nitrate concentrations were reduced to zero in the metalimnion and upper hypolimnion.

All pigments identified in traps were also found on the uppermost layer of bottom sediments in June-July 1997. On the western transect there was a steady in- crease of Chl- $a$ concentration from the shoreline towards the lake center, while on the eastern transect the increase in Chl- $a$ concentration started from a depth of approximately $8 \mathrm{~m}$ (Fig. 2A). The proportion of Chl- $a$ degradation products of all chlorophyllous pigments on the bottom (33-70\% along the western transect and 20$64 \%$ along the eastern transect) was mostly higher than in traps. The most abundant of the Chl- $a$ degradation products in bottom sediments was also Pheob4, which was from 5 to $185 \%$ of Chl- $a$ concentration. The Pheob4/Chl- $a$ ratio showed clear maxima at $12-14 \mathrm{~m}$ (Fig. 2B). The location of the Pheob4/Chl- $a$ ratio peak was more conspicuous on the eastern transect probably due to the fact that the sampling on the eastern transect was done within a single day, as opposite to the western transect during which sampling was spread over three weeks.

\section{DISCUSSION}

Lake Kinneret stratification commences, usually in March, and is followed by a rapid disappearance of oxygen from the hypolimnion (Serruya 1978). The existence of low oxygen concentrations normally persists for a short time span only, followed by denitrification, 
prior the commencement of sulfate reduction (the transition from $\mathrm{SO}_{4}{ }^{-2}$ to elemental $\mathrm{S}$ ), normally occurring in Lake Kinneret during April-May.
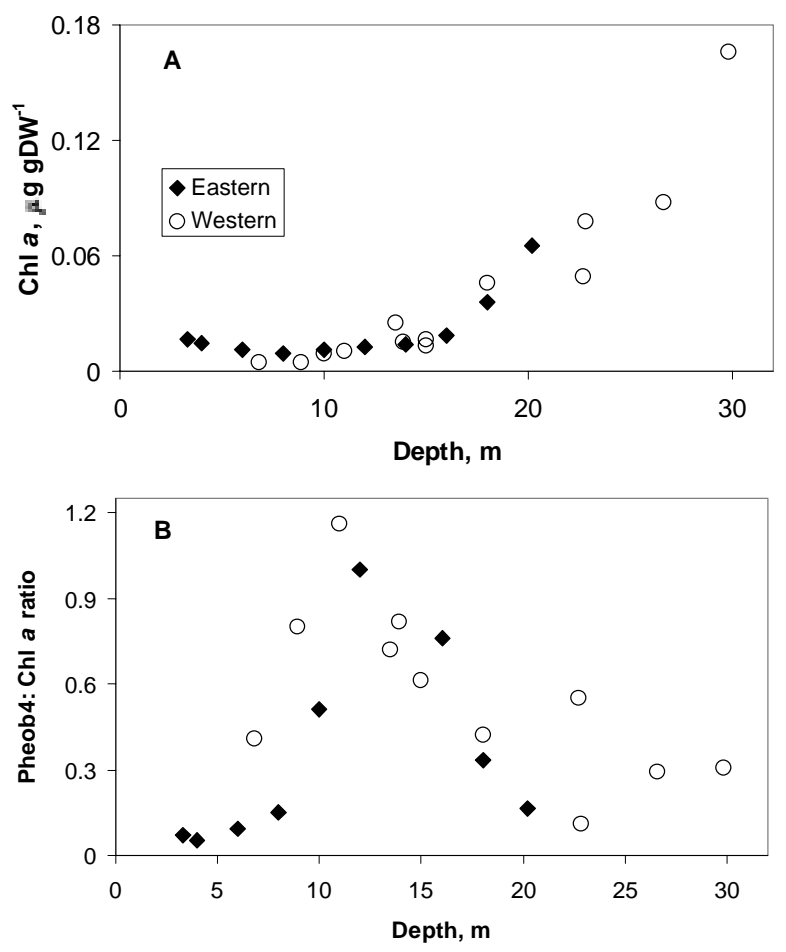

Fig. 2. Concentration of Chl- $a$ (A) and ratio of Pheob4 to Chl$a$ (B), in the uppermost layer of bottom sediment along two transects in Lake Kinneret. A western transect, that spanned from the western lakeshore towards lake center, was sampled from 10 June throughout 3 July and the eastern transect was sampled during a single day, on 6 July 1997.

The situation in June 1997 was atypical, as residual oxygen could be found in the hypolimnion for a relatively long period (Fig. 3), and redox values in the hypolimnion were positive (Nishri et al. 2000) while in a typical year in Lake Kinneret they are approximately $200 \mathrm{mV}$. The reason for that peculiarity was apparently related to the unusual succession of phytoplankton in 1997. In normal years, dense blooms of the dinoflagellate Peridinium gatunense characterize the lake phytoplankton succession from February to June (Pollingher 1986). In 1997 that peak of $P$. gatunense density was lacking and the flux of organic matter towards the bottom was reduced in April-May. The theca of P. gatunense, which constitute a large proportion of the sinking organic matter in April-May during typical years in Lake Kinneret (Zohary et al. 1998), are a fast-decomposing substance (Herzig et al. 1981). The lack of that component in the sinking organic matter was apparently the factor that slowed down oxygen consumption, and left relatively high concentrations of oxygen below the thermocline over a longer time span, following thermal stratification. At the beginning of June nitrate concen- trations in the hypolimnion was 300-400 ppb, an order of magnitude higher than the multi-annual average in Lake Kinneret. During the following two months it declined and then vanished completely, first in the BBL and then in the mid hypolimnion (Nishri et al. 2000).

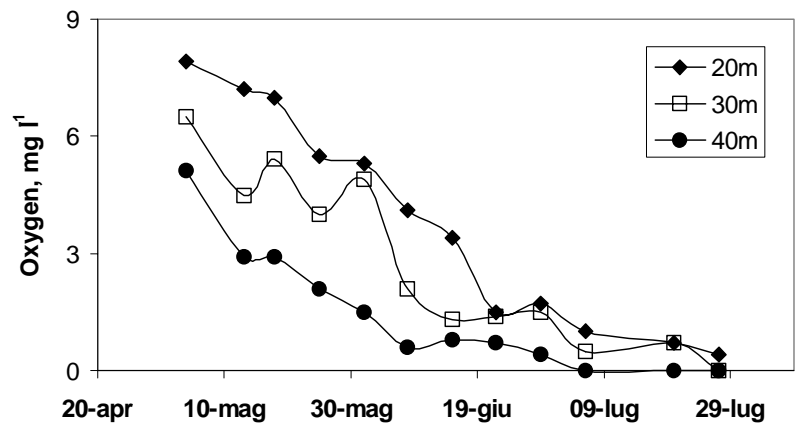

Fig. 3. Oxygen concentration in Lake Kinneret hypolimnion of Stn A, in May-July 1997.

The most prominent feature of the analysis of chlorophyllous pigments in June-July 1997 was the appearance of Pheob4 in material suspended in the water column, in sedimentation traps and in the superficial layer of bottom sediments. In our survey no Pheob4 was detected in the epilimnetic water column. In samples analyzed by a different HPLC system, coupled with a MS module (see Talbot et al. 1999) Pheob4 was tentatively identified as $13^{2}, 17^{2}$ cyclophaeophorbide- $a$ enol (CPP). CPP was recently found in bottom sediments from marine environments (Ocampo et al. 1999). Considering the high concentrations of CPP in fecal pellets of herbivores grazing on phytoplankton and CPP in marine sediments, Goericke et al. (2000) concluded that formation of this pigment may be one of the major pathways of Chl- $a$ degradation. Since the pigment separation was done on a different system than the system on which CPP was identified, we can not be sure that Pheob4 is CPP. When Pheob4 will show once again in Lake Kinneret, it will be isolated and characterized in order to enable a decisive identification.

Pheob4 was found to be dominant among other degraded chloropigments in anoxic hypolimnetic water at the time when nitrate concentration was rapidly decreasing. First, nitrate concentrations decreased in the BBL during June 1997, then, during July 1997, nitrogen concentration decreased in the mid hypolimnion (Nishri et al. 2000). During the end of each of the mentioned periods, the highest concentration of Pheob4 and the highest Pheob4/Chl- $a$ ratios were detected in the respective sections of the water column. With further development of anoxic conditions in the respective water layers (increase of hydrogen sulfide to about $3 \mathrm{mg} \mathrm{l}^{-1}$ ) Pheob4 vanished completely. In our previous studies of chloropigments in Lake Kinneret Pheob4 was found in low concentrations on the sediment in March, when the lake was fully oxygenated (Yacobi \& Ostrovsky 2000) 
and not detected at all in October-November, when sulfate reduction was the dominant process in the anoxic hypolimnion (Ostrovsky \& Yacobi 1999).

Pheob4/Chl- $a$ ratios of material collected in the near-bottom poisoned traps (and even in non-poisoned traps) were much lower than the maximum values detected in hypolimnetic water, indicating that the composition of sinking particles was not identical to the material suspended in the hypolimnion. In traps positioned in the BBL, Pheob4 concentrations and Pheob4/Chl- $a$ ratio were much higher in non-treated traps than in traps poisoned with formaldehyde. That finding indicates that settling particles were not an important source of Pheob4 in traps, and that the major part of Pheob4 was apparently mediated by biological degradation of Chl- $a$ within the traps. The oxygen-depleting and oxygen-depleted layers in Lake Kinneret sustain a large community of heterotrophic microorganisms (ciliates, flagellates and bacteria; Hadas \& Berman 1998), but, our study was not designed to identify, and thus can not pinpoint the organisms executing the transformation(s) of Chl- $a$ to Pheob4.

High Pheob4/Chl- $a$ ratios were also found in littoral traps positioned in the oxic water layers. The appearance of high amount of Pheob4 in the littoral traps $(\mathrm{H}$ and $\mathrm{M}$ ) located under epilimnetic oxic condition can be related to high proportion $(>80 \%)$ of material resuspended from the bottom and captured by these traps (Ostrovsky \& Yacobi 1999). Production of Pheob4 could take place in the bottom sediments where anoxic conditions develop even when the overlaying water is well oxygenated. Jones (1979) showed that nitrate reductase activity can take place in the bottom sediment beneath the oxygenated water and is associated with larger particles containing microcosms for nitrate respiration. In Lake Kinneret, Chlorobium phaeobacteroides, a strictly anoxic bacterium, could be found in uppermost littoral sediments (Ostrovsky et al. 1997; Ostrovsky \& Yacobi 1999), pointing out the existence of anaerobic microenvironments, within oxic layers.

The spatial variation of Pheob4/Chl- $a$ ratio in the upper-most layer of bottom sediments along the offshore transects showed that the peak of the ratio was at the depth of 12-14 m. It coincided with the position of thermocline-bottom interface, where, due to seiche movement, anoxic hypolimnetic water is repeatedly substituted by oxygenated epilimnetic water. The average transformation of Chl- $a$ to Pheob4, as it can be assessed from a comparison between poisoned and nonpoisoned traps, was about $8 \%$ per week (the average age of collected particles in traps was 1 week). Providing the average age of the collected sediments was 4-9 weeks (see Ostrovsky \& Yacobi 1999 and Yacobi \& Ostrovsky 2000, for details of calculation), about 32$72 \%$ of Chl- $a$ could have been be transformed to Pheob4 under proper ambient conditions. The specified range was found to be rather close to the actual range of
Pheob4/Chl- $a$ ratio in the hypolimnetic bottom sediments $(22$ to $55 \%)$. Thus, the longer period allowed for particle processing on the bottom sediments, as compared to the sedimentation traps, seems to be the factor responsible for higher Pheob4/Chl- $a$ ratios in the former.

\section{CONCLUSIONS}

The results presented in this study suggest that Pheob4-containing particles are apparently not an important component in the flux of particles sedimenting from the epilimnion towards the bottom sediment. The bulk of Pheob4 found in bottom sediment is a result of Chl- $a$ transformation in situ, under proper conditions. The comparison of formaldehyde-treated sediment traps to non-treated traps indicates the importance of biotic activity for Chl- $a$ transformation to Pheob4.

The occurrence of Pheob4 seems to correspond to unique environmental situation, a short time after oxygen consumption was completed, and prior the commencement of sulfate reduction. That period is usually very short in Lake Kinneret, but the unusual succession of phytoplankton caused modification in the pattern of oxygen consumption below the thermocline, and caused a relatively prolonged period of denitrification. Our sampling coincided with the timing of denitrification in the lake, revealing substantial concentrations of so far unrecognized chlorophyllous pigment. Further research is required to elucidate whether the occurrence of denitrification and the presence of Pheob4 are more than a coincidence. If the appearance of Pheob4 is recurrently linked to denitrification it can be used to pinpoint the localization of that process.

\section{ACKNOWLEDGMENTS}

We thank J. Easton and N. Koren for assistance in carrying out the field sampling. This research was partly supported by a grant from the German - Israeli Foundation (contract no. I-0416-026.08/95) and by Lake Kinneret Monitoring Program supported by the Israeli Water Commissioner.

\section{REFERENCES}

Barlow, R.G., P.H. Burkill, \& R.F.C. Mantoura. 1988. Grazing and degradation of algal pigments by marine protozoan Oxyrrhis marina. J. Exp. Mar. Biol. Ecol., 119: 119129.

Eckardt, C.B., B.J. Keely, \& J.R. Maxwell. 1991. Identification of chlorophyll transformation products in a lake sediment by combined liquid chromatography-mass spectrometry. J. Chromatogr., 557: 271-288.

Gieskes, W.W.C. 1991. Algal pigment fingerprints: clue to taxon-specific abundance, productivity and degradation of phytoplankton in sea and oceans. In: S. Demers (Ed.), Particle Analysis in Oceanography, NATO ASI Ser Vol. G27: 61-99.

Goericke, R., S.L. Strom, \& M.A. Bell. 2000. Distribution and sources of cyclic pheophorbides in the marine environment. Limnol. Oceanogr., 45: 200-211. 
Hadas, O., \& T. Berman. 1998. Seasonal abundance and vertical distribution of Protozoa (flagellates, ciliates) and bacteria in Lake Kinneret, Israel. Aquatic Microb. Ecol., 14: 161-170.

Herzig, R., Z. Dubinsky, \& T. Berman. 1981. Breakdown of Peridinium biomass in Lake Kinneret. In: H. Shuval (Ed.), Developments in Arid Zone Ecology and Environmental Quality, Proceedings of the 12th Scientific Conference of the Israeli Ecological Society. Balaban. Philadelphia: 179185 .

Jones, G.J. 1979. Microbial nitrate reduction in freshwater sediments. J. General Microbiol., 115: 27-35.

Klein, B., W.W.C. Gieskes, \& G.G. Kraay. 1986. Digestion of h.p.l.c. analysis of algal pigments. J. Plankton Res., 8: 827-836.

Koren, N., \& M. Klein. 2000. Rate of sedimentation in Lake Kinneret, Israel: spatial and temporal variations. Earth Surf. Process. Landforms, 25: 895-904.

Koren, N., \& I. Ostrovsky.(2001). Sedimentation in a stratified subtropical lake. Verh. int. Ver. Limnol., 27: (in press).

Leavitt, P. R. 1993. A review of factors that regulate carotenoid and chlorophyll deposition and fossil pigment abundance. J. Paleolimnol., 9: 109-127.

Nishri, A., J. Imberger, W. Eckert, I. Ostrovsky, \& Y. Geifman. 2000. The physical regime and the respective biogeochemical processes in the lower water mass of Lake Kinneret. Limnol. Oceanogr., 45: 972-981.

Ocampo, R., J.P. Sachs, \& D.J. Repeta. 1999. Isolation and structure determination of the very unstable $13^{2}, 17^{3}$-cyclopheophorbide $a$ enol from recent sediments. Geochim. Cosmochim. Acta, 63: 3743-3749.

Ostrovsky, I. 2000. The uppermost layer of bottom sediments: sampling and artifacts. Arch. Hydrobiol. Spec. Issues Advances in Limnology., 55: 243-255.

Ostrovsky, I., \& Y.Z. Yacobi. 1999. Organic matter and pigments in surface sediments: possible mechanisms of their

Received: June 2001

Accepted: August 2001 horizontal distribution in a stratified lake. Can. J. Fish. aquat. Sci., 56: 1001-1010.

Ostrovsky, I., D. Wynne, T. Bergstein-Ben Dan, A. Nishri, H. Li, Y.Z. Yacobi, N. Koren, \& R. Parparova. 1997. Spatial distributions of biogeochemical parameters in surface sediments. Air, Water and Soil Pollution, 99: 497-505.

Pollingher, U. 1986. Phytoplankton periodicity in a subtropical lake (Lake Kinneret, Israel). Hydrobiologia, 138: 127138.

Serruya, C. (Ed.). 1978. Lake Kinneret. Dr. Junk Publishers. The Hague: $501 \mathrm{pp}$.

Strom, S.L. 1993. Production of pheopigments by marine protozoa: Results of laboratory experiments analysed by HPLC. Deep-Sea Res., 40: 57-80.

Talbot, H.M., R.N. Head, R.P. Harris, \& J.R. Maxwell. 1999. distribution and stability of steryl chlorin esters in copepod faecal pellets from diatom grazing. Org. Geochem., 30: 1163-1174.

Vernet, M., \& C.J. Lorenzen. 1987. The relative abundance of pheophorbide a and pheophytin a in temperate marine waters. Limnol. Oceanogr., 32: 352-358.

Yacobi, Y.Z., \& I. Ostrovsky. 2000. Chloropigments in Lake Kinneret bottom sediments: mechanisms of spatial distribution during holomixis. Arch. Hydrobiol. Spec. Issues Advances in Limnology, 55: 457-469.

Yacobi, Y.Z., U. Pollingher, Y. Gonen-Zurgil, V. Gerhardt, \& A. Sukenik. 1996. HPLC analysis of phytoplankton pigments from Lake Kinneret with special reference to the bloom-forming dinoflagellate Peridinium gatunense (Dinophyceae) and chlorophyll degradation products. $J$. Plankton Res., 18: 1781-1796.

Zohary, T., U. Pollingher, O. Hadas, \& K.D. Hambright. 1998. Bloom dynamics and sedimentation of Peridinium gatunense in Lake Kinneret. Limnol. Oceanogr., 43: 175-186. 